\title{
3D Printing of Continuous Carbon Fibre Reinforced Thermo-Plastic (CFRTP) Tensile Test Specimens
}

\author{
Frank van der Klift' ${ }^{1}$, Yoichiro Koga ${ }^{2}$, Akira Todoroki ${ }^{2}$, Masahito Ueda ${ }^{3}$, Yoshiyasu Hirano ${ }^{4}$, \\ Ryosuke Matsuzaki ${ }^{5}$ \\ ${ }^{1}$ Department of Material Science and Engineering, Delft University of Technology, Delft, The Netherlands \\ ${ }^{2}$ Department of Mechanical Sciences of Engineering, Tokyo Institute of Technology, Tokyo, Japan \\ ${ }^{3}$ Nihon University, Tokyo, Japan \\ ${ }^{4}$ Japan Aerospace Exploration Agency, Tokyo, Japan \\ ${ }^{5}$ Tokyo University of Science, Chiba, Japan \\ Email: f.vanderklift@student.tudelft.nl
}

Received 20 November 2015; accepted 5 January 2016; published 8 January 2016

Copyright (C) 2016 by authors and Scientific Research Publishing Inc.

This work is licensed under the Creative Commons Attribution International License (CC BY).

http://creativecommons.org/licenses/by/4.0/

c) (i) Open Access

\section{Abstract}

A study was conducted to evaluate the current production capabilities of the Mark One ${ }^{\circledR}$ 3D printer in printing carbon fibre reinforced thermoplastic (CFRTP) tensile test specimens according to the JIS K 7073 by making use of fused deposition modelling. Several different types of CFRTP tensile test specimens are printed and are tensile tested in the longitudinal direction to obtain an overview of the mechanical properties of 3D printed CFRTP material. These properties are compared with the literature values known for composite materials to see if these agree. The main goal of this research is to increase the knowledge of the 3D printing process of CFRTP and to later use this knowledge to further improve the 3D printing process to obtain stronger 3D printed CFRTP materials.

\section{Keywords}

3D-Printing, Composites, Continuous Fibres, CFRTP

\section{Introduction}

Of the many production techniques, rapid prototyping is one of the most favourable in the current industry, because it reduces the development time of products and improves the flexibility for batch size products by helping 
in creating moulds, patterns and prototypes [1]. 3D printing especially helps in this regard due to the ability to create 3D models or prototypes of almost any complex shape and size [2]. Furthermore 3D printing has more advantages like low costs, fast production of samples and almost no waste material [3]. Disadvantages, however, are sometimes porous products and a stair-stepping effect in the $x$-y plane [4]. Currently more research is being conducted in the field of 3D printing of carbon fibre reinforced thermos-plastic (CFRTP) composites, which are being more widely used for structural applications especially in aerospace engineering and the automotive industry.

The 3D printing of CFRTP has been reported before in several cases. These carbon fibre reinforced plastic parts are usually relatively small due to the fact that the size of the part effects the strength of the composite. T. Okabe and N. Takeda [5] found in their research that the strength of a 3D printed composite decreases as its size increases. Most of the previously reported cases made use of short fibres and different types of techniques to accomplish the goal of making a CFRTP. Methods used were impregnation [6], mixing and extruding [7], and fused deposition modelling [8]. The 3D printing of CFRTP with continuous carbon fibres is more difficult but has also been achieved already, though the printed specimens are not fully in agreement with the rule of mixing known from the literature [9].

This research makes use of the previously obtained results from Namiki et al. [9] by combining fused deposition modelling with 3D printing to create tensile test specimens with continuously aligned carbon fibres. Namiki et al. found that by combining 3D printing with fused deposition modelling (FDM), the continuously aligned CFRTP tensile test bars could be printed. The tensile test specimens had a carbon fibre volume fraction of $1.0 \%$. However the tensile test specimens did not live up to the rule of mixing for composites because of delamination of the layers and void formation. Some solutions were suggested to prevent these problems from happening which included a preheater for the carbon fibres, changing the temperature of the print bed, and to decrease the diameter of the nozzle of the printer head.

In this study, the same approach is chosen, but now the Mark One ${ }^{\circledR} 3 \mathrm{D}$ printer is used, without taking the suggestions from Namiki et al. into consideration as of yet. The CFRTP is made by using Direct Digital Manufacturing (DDM) and is tested in tensile to determine the mechanical properties. In this research, samples created by using DDM are referred to as composite 2.0 materials, whereas composite 1.0 materials are composites manufactured by conventional methods. The tensile properties of composite 2.0 tensile test specimens are compared to those of the literature to see how well composite 2.0 materials perform. In case, the composite 2.0 material does not meet the rule of mixing stated for composite materials, the suggestions made by Namiki et al. will be taken into consideration in further studies.

\section{The Printing Process}

By making use of DDM the production of materials has reached an entirely new level. The materials made by DDM have some advantages over materials made by conventional, analogue production techniques. Before actually designing and printing the tensile test specimens, the printing process of the Mark One ${ }^{\circledR} 3 \mathrm{D}$ printer had to be understood first. For this purpose a sample of simple geometry was printed. Figure 1 shows one of the printed composite 2.0 samples used to understand the printing process of the Mark One ${ }^{\circledR} 3 \mathrm{D}$ printer, from now on referred to as Mark One ${ }^{\circledR}$.

The sample is a square of $45 \mathrm{~mm} \times 45 \mathrm{~mm} \times 3 \mathrm{~mm}$ in length, width and thickness respectively. The carbon fibres in the CFRTP are continuously aligned along the edge of the square. The centre of the square is pure matrix material, which is Nylon FFFR in this study. The FFF stands for Fused Filament Fabrication. For the rest of the paper the matrix material will be referred to as Nylon ${ }^{\circledR}$.

As can be seen in Figure 1 the carbon fibres are not completely continuous. There is a small $14 \mathrm{~mm}$ gap visible where there are no carbon fibres. The reason behind the discontinuity is caused by the printing pattern. In the case of the sample shown in Figure 1, the printer starts depositing material on the outside and moves inwards during the printing process. Because the printer head is close to the surface of the sample when printing, there is a chance of getting stuck while trying to print a fully continuous square. That is why the printer moves around the initial printed part and moves inwards this way. This inward movement is better visible in Figure 2 and different stages of the printing process are shown in Figure 3.

Once the printing process of the Mark One ${ }^{\circledR}$ was better understood the process of printing CFRTP tensile test specimens began. It was chosen to print three types of tensile test specimens, all of which are shown in Figure4. All of these tensile test specimens have the same thickness of $1.4 \mathrm{~mm}$ and all have 10 printed layers. The thickness of each layer was determined to be approximately $0.125 \mathrm{~mm}$. 


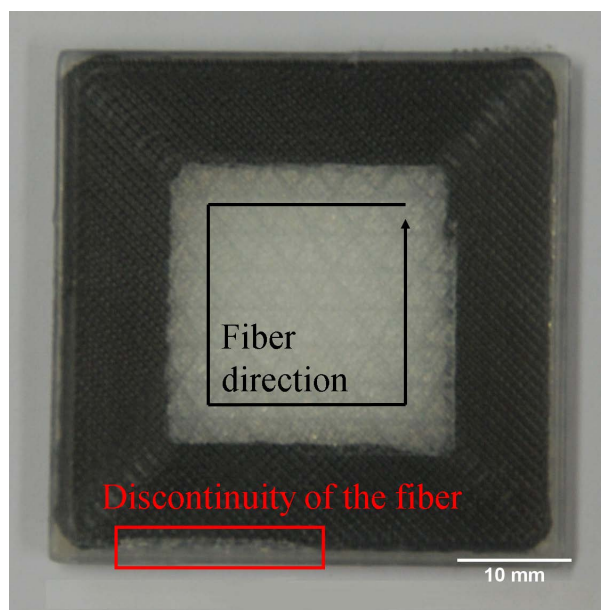

Figure 1. 3D printed composite 2.0 by the Mark One ${ }^{\circledR} 3 \mathrm{D}$ printer from Mark Forged ${ }^{\circledR}$. The sample is a $45 \mathrm{~mm}$ by 45 mm square with a thickness of $3 \mathrm{~mm}$. The square has a continuous CFRTP on the outside and matrix material in the centre. The printing direction is shown by the black arrow in the centre and the discontinuity in the CFRTP is visible within the red rectangle.

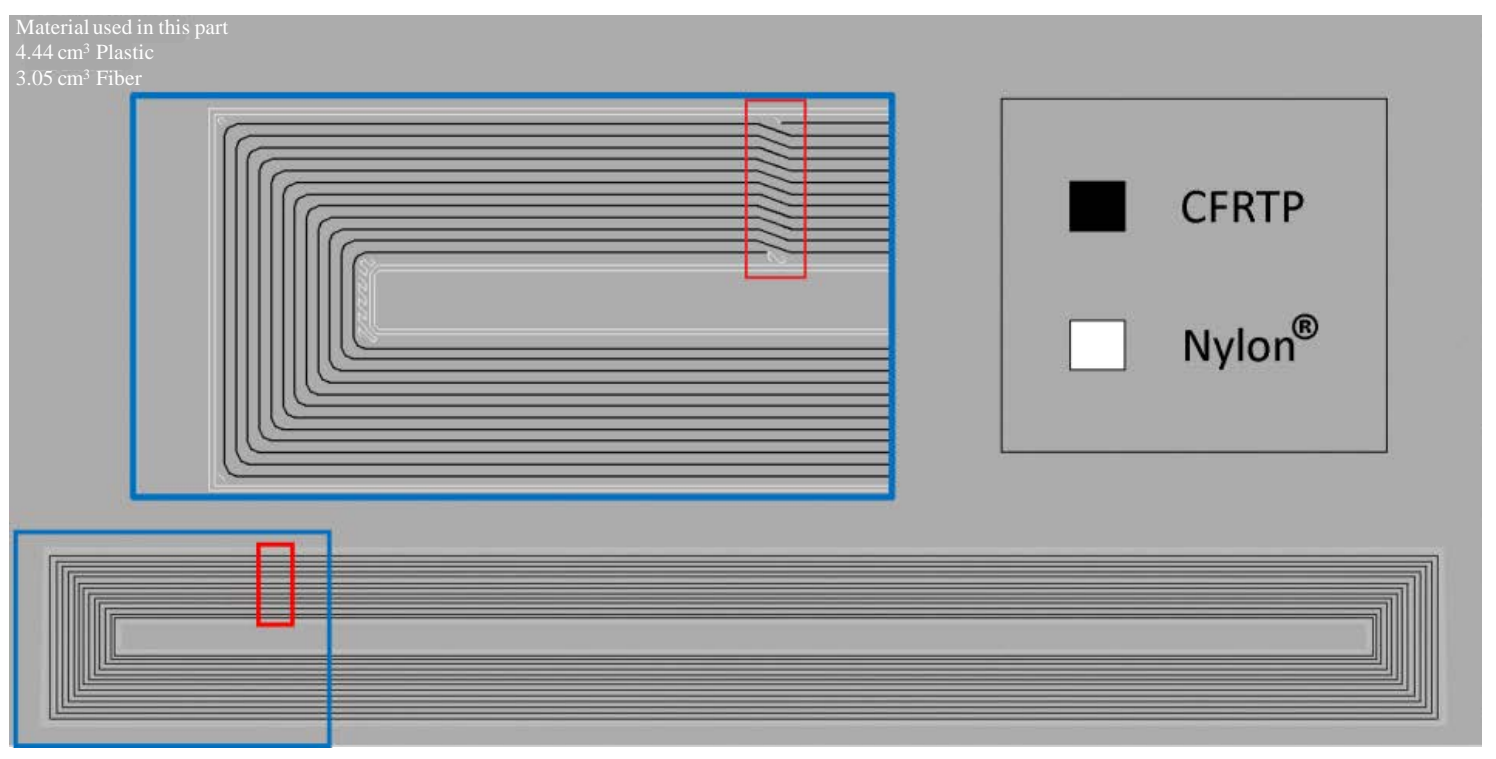

Figure 2. Sketch of the printed carbon fibre reinforced Nylon ${ }^{\circledR}$ specimen. The sketch is made with the Eiger ${ }^{\circledR}$ soft- $^{-}$ ware and shows an internal view of the printed sample. The discontinuity in the carbon fibres can be seen clearly here and is highlighted by the red rectangle.

The first type consisted of 10 layers of $100 \%$ Nylon ${ }^{\circledR}$ matrix material. From now on these samples are referred to as Nylon ${ }^{\circledR}$ samples.

The second type has 2 layers of $\mathrm{Nylon}^{\circledR}$, then 6 layers of CFRTP, and then 2 layers of Nylon ${ }^{\circledR}$ again. These specimens are from now on referred to as 6CF specimens.

The third type of specimen first have 4 layers of Nylon $^{\circledR}$, then 2 layers of CFRTP, and then 4 layers of Nylon ${ }^{\circledR}$ again. These specimens are from now on referred to as 2CF specimens.

As can be noted, there were no specimens printed that consist of 10 layers of CFRTP. The specimen always is one layer of Nylon ${ }^{\circledR}$ on the bottom and on the top of the CFRTP layers. The reason why there are layers on the bottom of the samples that only consist of Nylon ${ }^{\circledR}$ is so that the CFRP layers can be deposited more easily and do not disintegrate on the printing bed when the sample is removed. The Nylon ${ }^{\circledR}$ layers on the top of the sample are added for symmetry reasons. To minimize the discontinuity of the fibres in the specimens, the specimens were printed in pairs. Figure 2, which is a sketch of the specimens made with the software program called Eiger ${ }^{\circledR}$ 


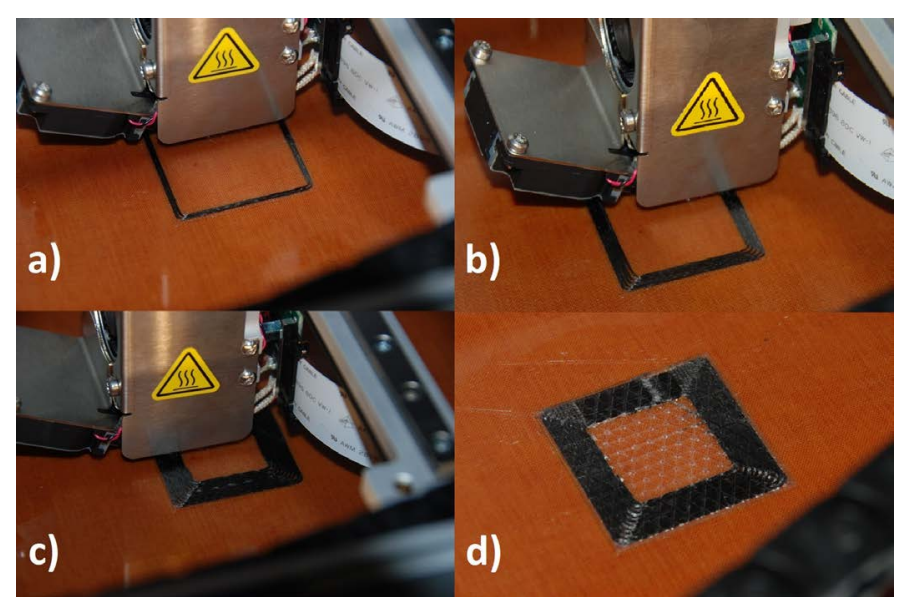

Figure 3. The printing process of the specimen from Figure 1. (a): The first 2 CFRTP continuous lines are printed. Here no Nylon ${ }^{\circledR}$ layer was printed. (b): Sample after 4 CFRTP lines. Note that the printing process starts on the outside of the square and ends in the centre. (c): Sample during the printing of the last CFRTP line. (d): Finished sample printed by the Mark One ${ }^{\circledR}$.

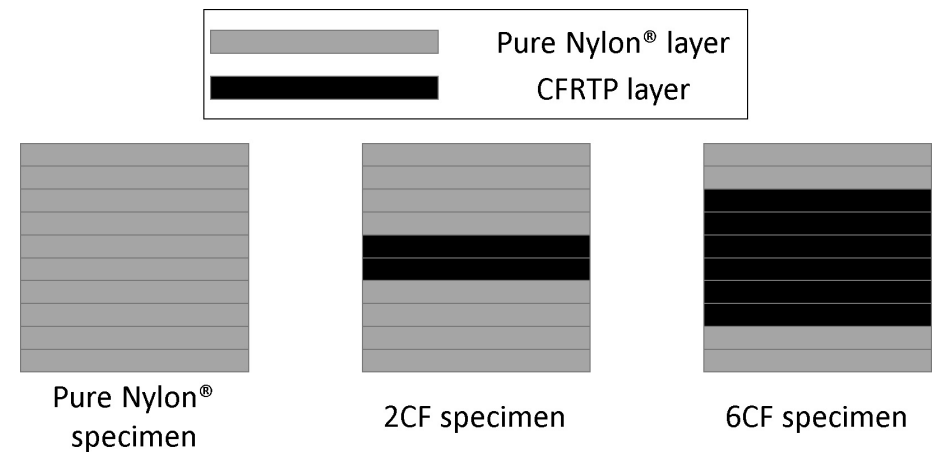

Figure 4. Schematic drawing of the three types of samples created by the Mark One ${ }^{\circledR}$. From left to right: $100 \%$ Nylon ${ }^{\circledR}$ specimen, 2CF specimen, 6CF specimen.

(powered by Mark Forged ${ }^{\circledR}$ ), shows the paired specimens. In this internal view the discontinuity in the carbon fibres is clearly visible.

\section{Experiments}

\subsection{Determining the Fibre Volume Fraction}

After printing two tensile test specimens were creating from the sample by using a sawing machine. The length of the specimens became $204 \mathrm{~mm}$ due to cutting away the discontinuity. The drawback of this method is that there is more waste material now. The specimens were ground to remove excess matrix material and tabs were attached to the ends of the specimens to be able to clamp the tensile test samples in the tensile test machine. The tensile test machine used in this study is the Shimadzu ${ }^{\circledR}$ AG-I $100 \mathrm{kN}$.

The first experiments performed were to increase the knowledge of the printing process and the printed materials. According to many textbooks the elastic modulus, $E$, of a composite (from now on referred to as elastic modulus) can be calculated using the rule of mixing. The rule of mixing for composites with continuous fibres is shown in Equation (1) for longitudinal loading.

$$
E_{c r r-L}=V_{f} \cdot E_{f}+\left(1-V_{f}\right) \cdot E_{n} .
$$

Here $E_{c r-L}$ is the elastic modulus in the longitudinal direction of one printed layer of CFRTP (in this case in the fibre direction), $V_{f}$ is the fibre volume fraction of the composite material, $E_{f}$ is the elastic modulus in the direction of the fibres, and $E_{n}$ is the elastic modulus of the matrix material (Nylon ${ }^{\circledR}$ in this case). 
However, all the variables concerning the carbon fibres and the Nylon ${ }^{\circledR}$ were unknown, because in this study it was chosen to use the carbon fibres and Nylon ${ }^{\circledR}$ supplied by the MarkForged ${ }^{\circledR}$ Company. These materials are patented and their mechanical properties could not be disclosed.

To obtain a theoretical value for the elastic modulus of the tensile test specimens it was decided to first determine the fibre volume fraction. For several specimens the matrix material was evaporated, according to JIS K 7075, to determine the volume fraction of the fibres. From these experiments the fibre volume fraction turned out to be $34.5 \%$. The other variables from Equation (1) would be determined from tensile test data to try and discover the type of the fibre that was used. The mechanical properties of the Nylon ${ }^{\circledR}$ were determined by testing specimens made completely of Nylon ${ }^{\circledR}$. These values were compared to the values from the MarkForged ${ }^{\circledR}$ datasheet [10].

\subsection{Tensile Tests}

To determine the elastic modulus, $E$, the strain, $\varepsilon$, and the ultimate tensile strength, $\sigma_{u t s}$, of the tensile test specimens, a series of tensile tests were performed. The test specimens were mounted in the Shimadzu ${ }^{\circledR}$ AG-I $100 \mathrm{kN}$ machine and were tested with a constant strain rate of $2 \mathrm{~mm} / \mathrm{min}$. Three types of tensile tests were performed.

The first type consisted of a set of 6 specimens with tapered tabs and 6 specimens with non-tapered tabs. Both were tested in tensile to determine if the shape of the tabs had any influence on the tensile properties of the samples. Since in the case of the composite 1.0 specimens that are made by the conventional methods, the shape of tabs does not affect the determined mechanical properties.

The second type was to test multiple specimens in two categories. The first category consists of the 6CF tensile test specimens. The second category was the 2CF tensile test specimens. Figure 5 shows a 6CF specimen printed by the Mark One ${ }^{\circledR}$.

The third type of test used $100 \%$ Nylon ${ }^{\circledR}$ specimens. The Nylon ${ }^{\circledR}$ samples were not ground, which gave them slightly larger dimensions than the 6CF and 2CF specimens. The dimensions of the Nylon ${ }^{\circledR}$ samples are shown in Table 1. All tensile tests were performed until failure occurred.

\section{Results and Discussion}

This section discusses the results and gives possible explanations on why certain results are the way they are. First a general comparison between composite 1.0 and composite 2.0 materials is made. Second, the results from the three types of tensile tests are discussed. Third the micro-structural analysis of the specimens is addressed and last the scattering of the data is shown.

\subsection{General Comparison}

To compare composite 1.0 with composite 2.0 it can be said that the production technique of the composite 2.0 is a lot faster as stated by Berman [3] and has less waste material than the conventional production techniques. However, due to the process of cutting and grinding away printed material in this study, the waste material went

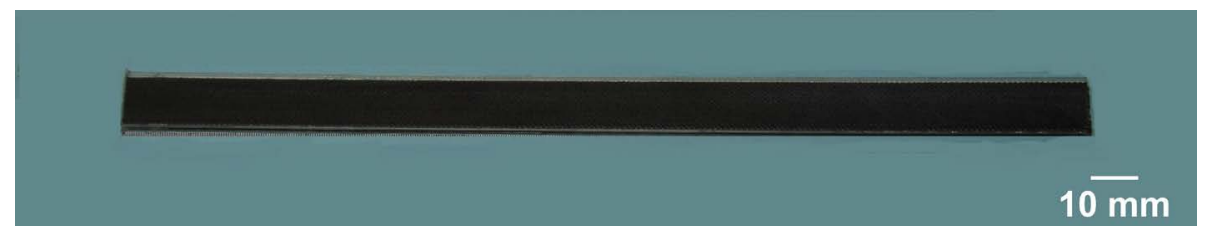

Figure 5. Sample with 6 layers of CFRTP printed by the Mark One ${ }^{\circledR}$. The sample still has to be ground and the tabs still have to be attached.

Table 1. Dimensions of Nylon ${ }^{\circledR}$ tensile test specimens.

\begin{tabular}{cc}
\hline Dimensions, unit & Value \\
\hline Length, mm & 204 \\
Width, mm & 12.5 \\
Thickness, mm & 1.4 \\
\hline
\end{tabular}


up to roughly $15 \%$, making the production technique used in this study less cost-effective. The production time, however, still is shorter than that of the conventional production techniques, since it takes less than 2 hours to make the sample shown in Figure 5.

\subsection{Nylon $^{\circledR}$}

In total 3 Nylon ${ }^{\circledR}$ samples were tested in tensile. The results from these tests are shown in Figure 6. From these results the elastic modulus was determined to be $900 \mathrm{MPa}$ for $0 \%$ to $0.5 \%$ strain. These results are similar to the properties of Nylon-6 or Nylon-66 with 3.5\% wetting, which occurs at a relative humidity of $60 \%$ to $70 \%$ [11]. This air humidity is the same as the environmental condition of the tensile tests. The resulting mechanical properties of the Nylon ${ }^{\circledR}$ are shown in Table 2.

\subsection{Specimens with 6 CFRTP Layers}

The results from the 6CF specimen tensile tests are displayed in Figure 7. It can be seen that the strain of the 6CF specimens varies roughly between $1.3 \%$ and $2.0 \%$. The ultimate tensile strength at failure varies between $370 \mathrm{MPa}$ and $520 \mathrm{MPa}$ and has an average of 464.4 MPa. The first non-linear part of the graph occurred because the specimens were not pre-strained in the clamps. The elastic modulus was calculated by looking at the slope of the stress-strain curve from Figure 7 and was calculated to be $35.7 \mathrm{GPa}$. This is the elastic modulus of the specimen as a whole. To determine the elastic modulus of the fibres, the elastic modulus of one single CFRTP layer was determined by using Equation (2).

$$
E_{t}=\frac{n_{n}}{n_{t}} \cdot E_{n}+\frac{n_{c f r}}{n_{t}} \cdot E_{c f r-L} .
$$

Here $E_{t}$ is the elastic modulus of the specimen in total, $n_{n}$ is the number of Nylon ${ }^{\circledR}$ layers in the specimen, $n_{t}$ is the total number of printed layers in the specimen and $E_{c r-L}$ is the elastic modulus of one printed layer of CFRTP. The resulting $E_{c f r-L}$ from Equation (2) can be inserted in Equation (1) to obtain the elastic modulus of the carbon fibre bundle, which is $173.24 \mathrm{GPa}$. This value is too low for a carbon fibre bundle so there are either irregularities in the fibres, in between the fibres, or even in between the CFRTP layers themselves.

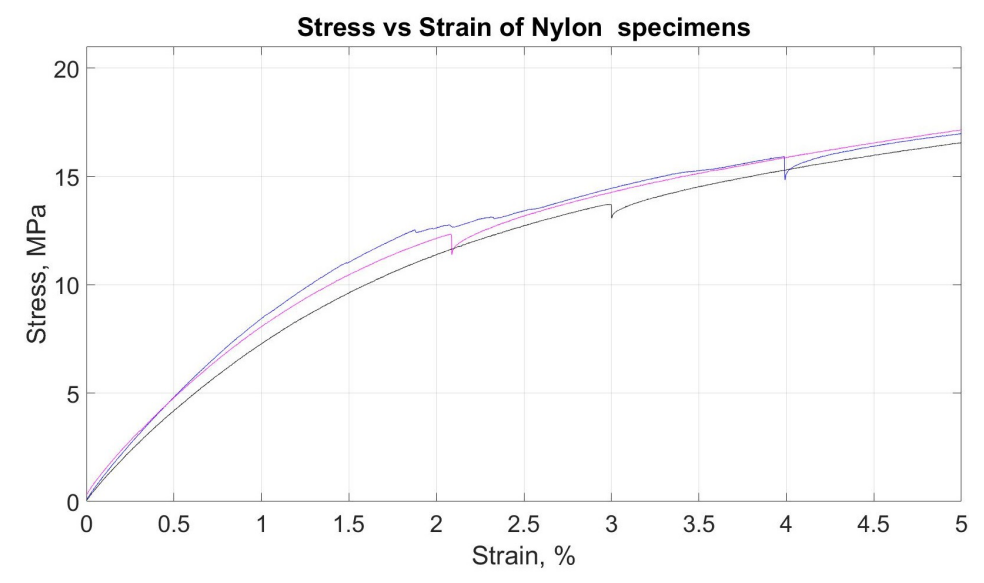

Figure 6. Stress-Strain curve of the $100 \%$ Nylon ${ }^{\circledR}$ specimens. The tensile tests were performed with a constant strain of $2 \mathrm{~mm} / \mathrm{min}$. Specimens were tested until failure occurred.

Table 2. Mechanical properties of TORAYCA ${ }^{\circledR}$ T300 tow and Nylon ${ }^{\circledR}$.

\begin{tabular}{ccc}
\hline Dimensions, unit & TORAYCA $^{\circledR}$ T300 & Nylon $^{\circledR}$ (dry/water-absorbed) \\
\hline Tensile strength, MPa & 3530 & $85 / 50(2.5 \%)$ \\
Tensile modulus, GPa & 230 & $2.8 / 1.3(3.5 \%)$ \\
Strain, $\mathrm{mm} / \mathrm{mm}$ & 0.015 & $0.05 /-$ \\
\hline
\end{tabular}




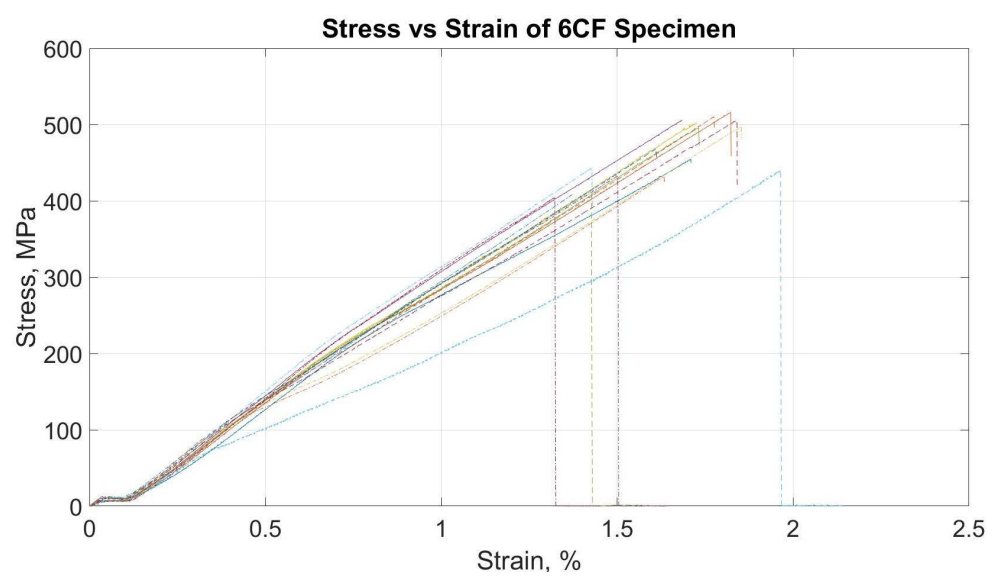

Figure 7. Stress-strain curve of 6CF specimen undergoing a tensile test with a constant strain of $2 \mathrm{~mm} / \mathrm{min}$. Specimens were tested until failure occurred.

During the examination of the 6CF specimen after failure, there were a few important things to note. The first thing was that the specimens almost always failed near the tabs, which is where the specimens were clamped in. In all cases these areas did not have the smallest cross section area of the specimen, which is where the specimens were expected to fail. Figure 8 shows the two types of failures of the 6CF specimens. One is an incomplete failure, where the fibres have failed but the Nylon ${ }^{\circledR}$ is still attached. The other is a complete failure, where both the Nylon ${ }^{\circledR}$ and the fibres have failed. The fractures occurred just below the tabs.

\subsection{Specimens with 2 CFRTP Layers}

A graph showing the results of the 2CF specimen is shown in Figure 9. The same initial non-linear response can be observed in both the 2CF and the 6CF specimens. The strain of the 2CF specimens is between $0.8 \%$ and $1.3 \%$ and the ultimate tensile strength varies between $128 \mathrm{MPa}$ and $171 \mathrm{MPa}$, which is about one third of that of the 6CF specimens. One of the 2CF samples failed at only $1.5 \mathrm{~mm}$ strain and $85 \mathrm{MPa}$ tensile strength (see Figure 9). Upon further investigation it seemed that this sample had a discontinuity in the carbon fibres. (Asame sort of discontinuity was shown in Figure 1).

As expected, the specimen failed at the area where the discontinuity was located as can be seen from Figure 10. The total length of the discontinuity was $7 \mathrm{~mm}$ and the fracture occurred at the place where the fibres ended.

By using Equations (1) (2) the elastic modulus of the carbon fibres in the 2CF specimens was determined to be 231.4 GPa. This is a valid value for a carbon fibre bundle which, together with the result obtained from the 6CF specimens, indicates that a specimen deviates more from the rule of mixture (Equation (1)) when it has more CFRTP layers.

The mechanical properties of the CFRTP layer are shown in Table 2.

\subsection{Microstructural Analysis}

The analysis of the micro-structure of the composite 2.0 material was performed to help determine the type of carbon fibre used. A picture taken by the HiROX ${ }^{\circledR}$ Digital Microscope KH-1300 is shown in Figure 11. The image was taken at a magnification of 700 times and shows a single bundle of carbon fibres embedded in an Acrylate Scandia Quick ${ }^{\circledR}$ matrix.

From Figure 11 the number of fibres in each fibre bundle was calculated to be 1000 fibres per bundle. By using this data and knowing the cross-section of the samples the carbon fibre properties could be estimated.

When considering the fibre density of the specimens, the value of the ultimate tensile strength was calculated to be $3442 \mathrm{MPa}$ for the 6CF specimens and $3335 \mathrm{MPa}$ for the 2CF specimens. These values are close to the value of the TORAYCA ${ }^{\circledR}$ T300 tow made by TORAY ${ }^{\circledR}$ as can be seen from the datasheet [12].

Besides of a single carbon fibre bundle, images were also made of the cross-section area of the specimens. Figure 12 shows the cross-section area of 6CF and 2CF specimens.

As can be seen in Figure 12 the cross-section of the 6CF specimen shows a lot more void area than the crosssection of the 2CF specimen. The larger amount of void area is one of the reasons why the 6CF specimens did 


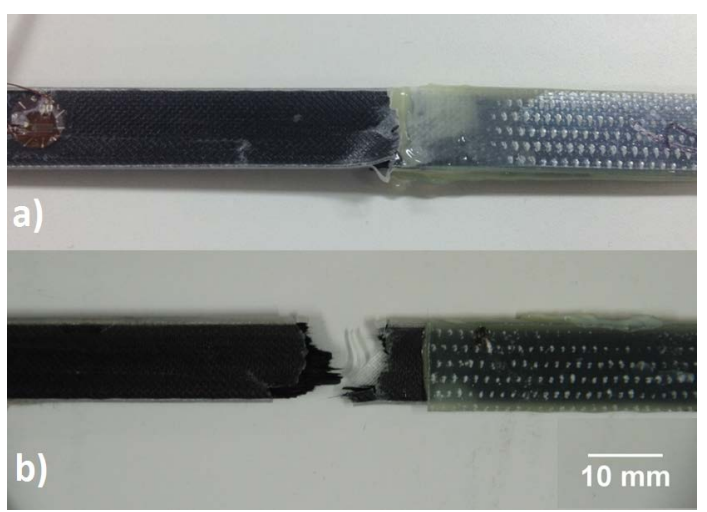

Figure 8. Two 6CF specimens after tensile testing. The specimens failed just below the tabs. (a): It shows an incomplete failure of the specimen. (b): It shows a complete failure of the specimen.

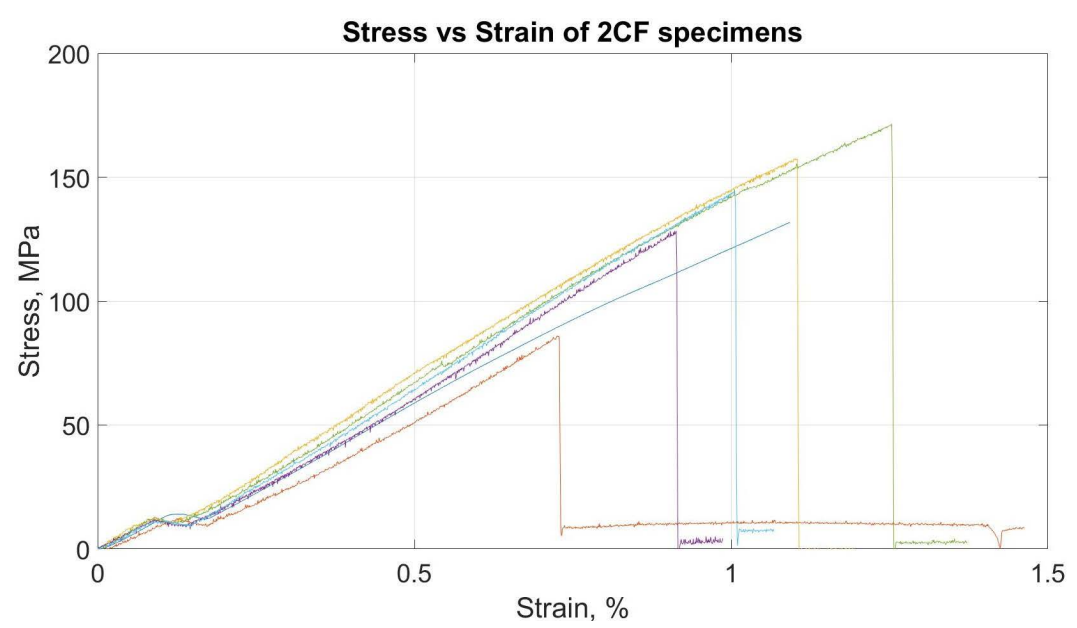

Figure 9. Stress-strain curve of 2CF specimen undergoing a tensile test with a constant strain of $2 \mathrm{~mm} / \mathrm{min}$. Specimens were tested until failure occurred.

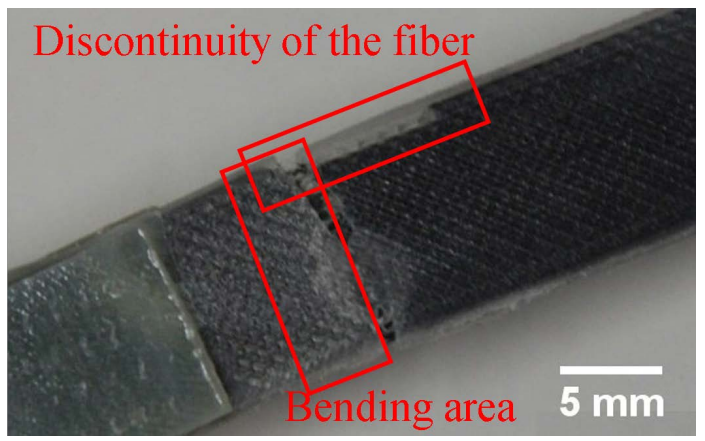

Figure 10. 2CF specimen with a discontinuity of $7 \mathrm{~mm}$ in the carbon fibres. The specimen failed at a stress of only $85 \mathrm{MPa}$ and happened at the location where the fibres ended.

not fully live up to the rule of mixing as stated by Equation (1).

This leads to an interesting discovery for future research, which is studying the effect of the arrangement of layers on the properties of the composite 2.0 material. It is certainly possible to print the CFRTP and Nylon ${ }^{\circledR}$ layers alternatively, as long as the top and bottom layer are Nylon ${ }^{\circledR}$. Future research will be conducted on this topic. 


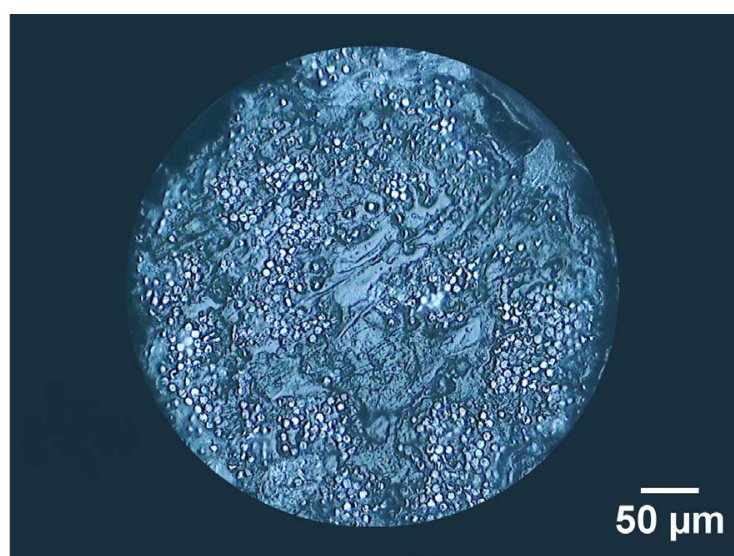

Figure 11. Picture taken by the HiROX ${ }^{\circledR}$ digital microscope KH-1300 at a magnification of 700 times. The image shows a single bundle of carbon fibres embedded in an Acrylate Scandia Quick ${ }^{\circledR}$ matrix.

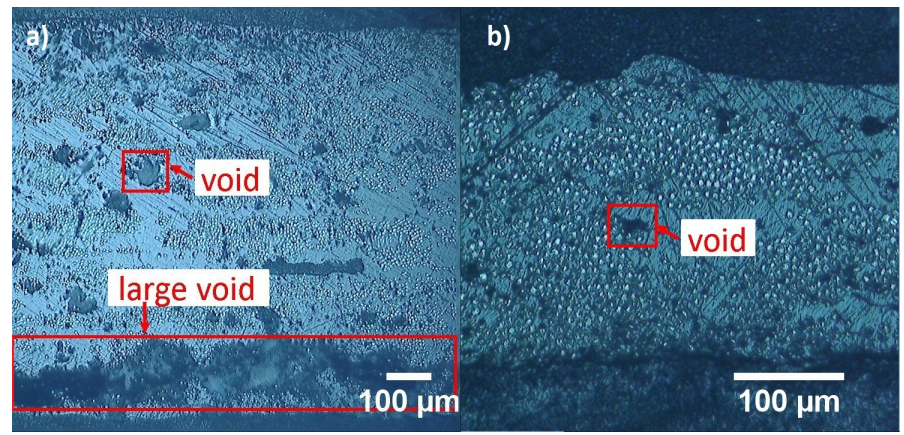

Figure 12. Cross-sections of the CFRTP specimens. (a): It shows a cross-section of the 6CF specimen. (b): It shows the cross-section of a 2CF specimen. As can be seen, there is a lot more void area visible in (a) than in (b).

\subsection{Data Scattering}

According to Maekawa et al. [13] the tensile stress of CFRP laminate materials varies around $10.7 \%$ at room temperature. To see if the same holds for the specimens created by the Mark One ${ }^{\circledR}$ a box plot of the results, which is displayed in Figure 13, was constructed. Note that three cases of premature failure have been taken out of Figure 13, since these gave an incorrect interpretation of the results.

It can be seen from Figure 13 that the scattering of the data of both the 6CF and the 2CF specimens varies quite a bit but the majority of the data is within a $10.7 \%$ range of the median. For the 6 CF specimens $75 \%$ is within a $10.7 \%$ of the median. All of the 6CF data is within $12.8 \%$ deviation of the median. This comes close to the value for CFRP laminate materials as determined by Maekawa et al. For the 2CF specimens only 5 (the one specimen that failed prematurely has been left out) specimens were tested, which is why the scatter is less accurate. Here only $60 \%$ is within $10.7 \%$ of the median. All of the 2CF data is within a $16.95 \%$ scatter of the median.

\section{Conclusions}

By using the Mark One ${ }^{\circledR}$, it was possible to 3D print CFRTP specimens with continuously aligned carbon fibres.

There happened to be some discontinuities but by adjusting the printing process and by cutting conveniently, some of these discontinuities could be avoided. From experiments, it turned out that discontinuities of the fibres led to premature failure in the areas where the fibres were absent and should be avoided at all costs since it severely decreased the tensile strength of the composite 2.0 material. The tensile tests showed promising results on the elastic modulus of both the 2CF and 6CF composite 2.0 specimens and showed that the specimens came close to the rule of mixing for composites 1.0 materials in the case of the 2CF specimens but not for the 6CF 


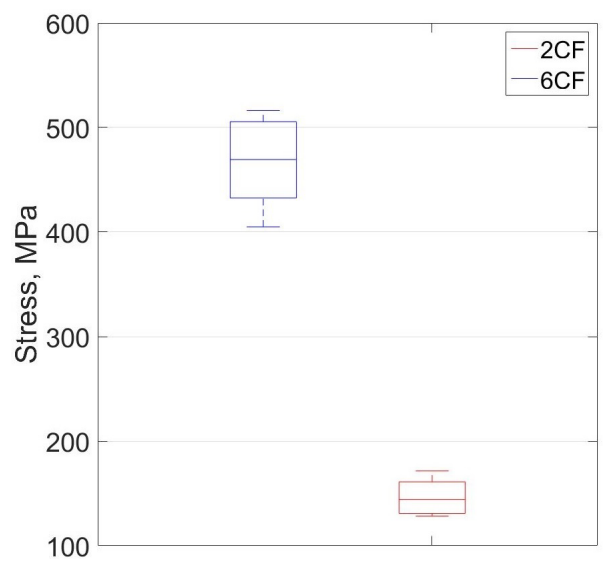

Figure 13. Box plot showing the data scattering of the ultimate tensile stress for 6CF (blue) and 2CF (red) specimens.

specimens. This is due to the fact that the cross-section area of the 6CF specimens contains more void areas than the 2CF specimens.

\section{References}

[1] Yan, X. and Gu, P. (1996) A Review of Rapid Prototyping Technologies and Systems. Computer-Aided Design, 28, 307-318. http://dx.doi.org/10.1016/0010-4485(95)00035-6

[2] Rengier, F., Mehndiratta, A. and von Tengg-Kobligk, H. (2010) 3D Printing Based on Imaging Data: Review of Medical Applications. International Journal of Computer Assisted Radiology and Surgery, 5, 335-341. http://dx.doi.org/10.1007/s11548-010-0476-X

[3] Berman, B. (2012) 3-D Printing: The New Industrial Revolution. Business Horizons, 55, 155-162. http://dx.doi.org/10.1016/j.bushor.2011.11.003

[4] Pham, D.T. and Gault, R.S. (1998) A Comparison of Rapid Prototyping Technologies. International Journal of Machine Tools \& Manufacture, 38, 1257-1287. http://dx.doi.org/10.1016/S0890-6955(97)00137-5

[5] Okabe, T. and Takeda, N. (2002) Size Effect on Tensile Strength of Unidirectional CFRP Composites—Experiment and Simulation. Composite Science and Technology, 62, 2053-2064. http://dx.doi.org/10.1016/S0266-3538(02)00146-X

[6] Czyzewski, J., Burzynski, P., Gawel, P. and Meisner, J. (2009) Rapid Prototyping of Electrically Conductive Components Using 3d Printing Technology. Journal of Materials Processing Technology, 209, 5281-5285. http://dx.doi.org/10.1016/j.jmatprotec.2009.03.015

[7] Tekinalp, H., Kunc, V., Velez-Garcia, G., Duty, C., Love, L., Naskar, A., Blue, C. and Ozcan, S. (2014) Highly Oriented Carbon Fibre-Polymer Composites via Additive Manufacturing. Composites Science and Technology, 105, 144-150. http://dx.doi.org/10.1016/j.compscitech.2014.10.009

[8] Ning, F., Cong, W., Qiu, J., Wei, J. and Wang, S. (2015) Additive Manufacturing of Carbon Fibre Reinforced Thermoplastic Composites Using Fused Deposition Modeling. Composites Part B: Engineering, 80, 369-378. http://dx.doi.org/10.1016/j.compositesb.2015.06.013

[9] Namiki, M., Ueda, M., Todoroki, A., Hirano, Y. and Matsuzaki, R. (2014) 3D Printing of Continuous Fibre Reinforced Plastic. Proceedings of the Society of the Advancement of Material and Process Engineering 2014, Seattle, 2-5 June 2014, 6.

[10] (2015) MarkForged, Mechanical Properties, 9. https://markforged.com/materials/data-sheet/

[11] Toray, AMILAN ${ }^{\circledR}$ Data Sheet, No. CM1017-PA6.

[12] Toray, Technical Data Sheet, No. CFA-019.

[13] Maekawa, Z., Hamada, H., Yokoyama, A. and Ishibashi, S. (1991) WS4a5-Reliability Evaluation on Mechanical Characteristics of CFRP. Mechanical Behaviour of Materials VI. Proceedings of the Sixth International Conference, Kyoto, Japan, 29 July-2 August 1991, 677-682. http://dx.doi.org/10.1016/b978-0-08-037890-9.50114-9 